\title{
Tomás Harris y la memoria fracturada de América
}

\section{Felipe Oliver}

Felipe Oliver es doctor en literatura por la Pontificia Universidad Católica de Chile. En el 2006 obtuvo la Beca Roque Esteban Scarpa, distinción que otorga la Universidad Católica de Chile cada cuatro años a un estudiante internacional destacado. Actualmente trabaja como profesor e investigador en el Departamento de Letras Hispánicas de la Universidad de Guanajuato. Es autor del libro Para una poética de la Narcoliteratura (México: Universidad de Guanajuato, 2012). 
PALABRAS CLAVE:

Poesía chilena; Tomás Harris; poesía y dictadura; poesía y tortura; conquista de América.

KEYWORDS

Chilean Poetry; Tomás

Harris; poetry during military

government; poetr $\gamma$ and torture;

Conquest of the Americas.

\section{Resumen}

Escrito durante la dictadura de Augusto Pinochet, Cipango [1992] pone en escena la alianza entre las escrituras oficiales y los intereses políticos de la ciudad letrada. En efecto, en su magnífico poemario Harris revisa no precisamente la historia sino cómo y bajo qué condiciones de poder se escribió el discurso sobre la fundación del Nuevo Mundo, detectando en la violencia y la tortura un vínculo entre la Conquista de la Indias y el reciente gobierno militar chileno. Así, a través de los silencios y la sistemática interrupción del verso, Harris "utiliza" al poemario como un instrumento para develar las fracturas del discurso histórico.

ABSTRACT

Cipango [1992], written during Augusto Pinochet dictatorship, displays the alliance between the official writings and the political interests in the lettered city. In fact, in his magnificent collection of poems, Harris not only reviews the history but also how and under which conditions of power the discourse of the foundation of the New World was written. The poet also establishes a link between the Conquest of the Americas and the recent Chilean military government due to their practices of violence and torture. Thus, through silences and the systematic interruption of the verse, Harris "uses" his poems as an instrument to reveal the fractures of the historical discourse. 
TOMÁS HARRIS Y LA MEMORIA FRACTURADA DE AMÉRICA

FELIPE OLIVER

Cipango [1992] de Tomás Harris reúne cinco poemarios menores escritos de forma independiente y autónoma: Zonas de peligro [1985], La forma de los muros (escrito entre I980 y 1982 pero inédito hasta 1992), Diario de navegación [1986], Último viaje [1987] y Cipango [1992]. Sin embargo, hay una continuidad semántica que atraviesa a todos ellos, de ahí que hayan sido editados en un sólo volumen y puedan leerse como un gran proyecto sobre la memoria fracturada de América. En efecto, en su magnífico poemario, Harris revisa no precisamente la historia sino cómo y bajo qué condiciones de poder se escribió el discurso sobre la fundación del Nuevo Mundo, detectando en sus manifestaciones de violencia y de tortura un vínculo entre la Conquista de la Indias y el reciente gobierno militar chileno. En el proceso, el texto devela la alianza entre las escrituras oficiales y los intereses políticos de la ciudad letrada, siempre dispuesta a silenciar las voces disidentes. Coalición que se reproduce y verifica hasta nuestros días. Tal es, en síntesis, la lectura crítica que aquí propongo: el poemario como un instrumento para develar las fracturas del discurso histórico a través de los silencios y la sistemática "fractura" del verso. Desde luego, abrir el análisis a los cinco poemarios significaría perder concreción ya que el corpus crecería tanto que sólo permitiría una visión panorámica. Así, en aras de la profundidad y la brevedad me concentraré preferentemente en Zonas de peligro, si bien es cierto que en lo posible aludiré a otros textos.

Un aspecto fundamental de la poesía de Harris es la continua fisura del verso, por lo que en una primera aproximación armaremos el análisis explicando los silencios. Transcribamos un pocma:

\footnotetext{
El horror te inventa el Hotel King el baldío de Orompello te inventa una cárcel oculta al otro extremo de la Concepción la vida y la muerte lo mismo en
} 
CARACOL 5 / VÁRIA

\begin{abstract}
cada Zona de Peligro (hacían apuestas sobre quién de una cuchillada abría al hombre de por medio o le cortaba la cabeza de un piquete o le descubría las entrañas) están en el centro mismo de las orgías de tu corazón lo mismo ayer hoy mañana pasará el deseo escociéndote las heridas las marcas las señales por aquí por allá rojas la vida y la muerte en cada Zona de Peligro el horror te inventa el horror no se inventa rojo a rojo sangre a semáforo a cuerpo rasgado desflorado hasta la muerte acá al Sureste de La Concepción del Imperio de este baldío donde no se pone el sol una larga y angosta faja de muerte sin oasis para detenerse a respirar jadear estás en el centro mismo de las orgías de tu corazón Hotel King muros adentro lo mismo ayer hoy el año de mil quinientos y veinte fue un gran tirano muy de propósito y con mucha gente sin temor alguno de Dios ni compasión de humano linaje.

(Harris, 96, 49)
\end{abstract}

No está de más recordar la teoría de Jean Cohen' según la cual los espacios en blanco en un poema, el que sea, obedecen siempre a una pausa. Y la pausa a su vez marca el final del verso precedente y el inicio del verso subsiguiente, pues este debe recitarse en un solo acto fónico, de golpe por decirlo de algún

I De acuerdo con Cohen, el rasgo distintivo del verso es el "trozado" o la utilización del espacio en blanco. Dicho espacio en blanco es un signo gráfico para indicar una pausa o silencio: la ausencia de letras simboliza la ausencia de voz. Véase "Versificación" en La estructura del lenguaje poético. 
TOMÁS HARRIS Y LA MEMORIA FRACTURADA DE AMÉRICA

FELIPE OLIVER

modo. El que los blancos ocupen una misma línea, como ocurre por ejemplo en la undécima línea con ayer/hoy/mañana/pasará indica entonces la sucesión de cuatro versos independientes. No obstante, el que figuren "juntos" y en el mismo "renglón" debe justificarse semánticamente. Es decir, al interior del poema debe explicarse y entenderse la peculiar disposición de los versos, la espacialización de la palabra sobre la hoja de papel. En el caso particular que aquí nos compete, el espacio en blanco que media entre ayer y hoy sirve para acentuar el espacio de indeterminación temporal que separa al pasado del presente. En otras palabras, el poema literalmente impone un espacio temporal para distanciar al ayer del hoy. Sin embargo, comienzo a demorarme en un poema específico cuando corresponde pensar la continua fractura del verso como una norma que cruza y recorre todo el poemario. La irrupción de la pausa es el sello distintivo de la poesía harriana, por lo que el silencio se impone como un primer acercamiento oportuno para la concreción de la hipótesis.

La lectura obvia del texto, la falsa conciencia, para usar la terminología de Adorno $^{2}$, apunta hacia la tortura. Después de todo, el poemario fue escrito durante la dictadura militar y en el último poema de la primera parte, "Zonas de peligro (Final)", se menciona explícitamente el año de i973:

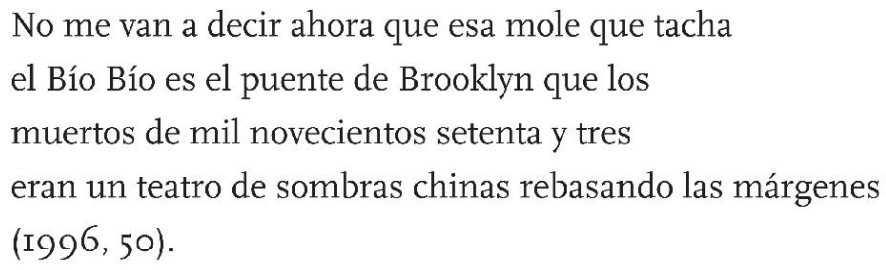

En un conocido trabajo titulado "Discurso sobre poesía lírica y sociedad", Adorno establece que "la corriente subterránea colectiva de la poesía lírica empuja hacia arriba en los más distintos lugares, primero como fermento de la misma expresión individual, pero luego también acaso como anticipo de una situación que rebasa positivamente a la mera individualidad" $(2003,58)$. 
Apenas sí es necesario recordar que I973 constituye una fecha clave en la historia reciente de Chile gracias al golpe de estado encabezado por el general Augusto Pinochet y la subsecuente dictadura militar que habría de prolongarse por casi dos décadas. Por lo demás, y con especial hincapié en La forma de los muros y Diario de navegación, el cuerpo humano es sometido a todo tipo de humillaciones y vejaciones, como la inoculación de coca cola ${ }^{3}$ en las venas. Pero ya desde Zonas de peligro hay claros indicios de tortura, baste con revisar los versos contenidos en el paréntesis del poema trascrito líneas arriba. En síntesis, en un primer acercamiento podemos concluir que el verso "se rompe" pues lo narrado, o sea lo que acontece en el interior del Hotel King (transformado ya en un campo de exterminio), no es únicamente la experiencia erótica sino un acto de tortura, y la tortura implica la horadación del cuerpo y, por tanto, de la escritura. ¿Qué significa la división silábica en palabras como "cár-cel”, “Concep-ción”, etcétera, un simple problema de espacio tipográfico o un atentado deliberado a la palabra? Citando la acertada lectura de Magda Sepúlveda,

la ciudad de Concepción had sido devastada desde el acto de fundación o bautismo verbal, de ahí que el asolamiento del territorio se dobla en el lenguaje del poema, donde

3 En un poemario posterior titulado Itaca (2001), Harris utiliza de manera obsesiva la imagen de un yo lírico "anestesiado" por una inyección diaria de "una dosis de coca cola". Sin embargo, Itaca plantea la problemática de un sujeto pasivo "encadenado" al televisor. I.a "realidad" del yo lírico aparece nuevamente fragmentada pero ya no por la experiencia de la tortura sino por la multiplicad y dispersión de imágenes que distinguen nuestra interacción con el mundo como simples espectadores de los medios masivos de comunicación. No deja de ser interesante que Harris recupere la inoculación de coca cola para ponerla a funcionar en un contexto diferente pero igualmente violento. Al respecto de Itaca, véase: Rodríguez, José Manuel. "Harris, voyeur adelantado". Anales de Literatura Chilena, n. 10. Año 9, Diciembre 2008, 137-143. 
TOMÁS HARRIS Y LA MEMORIA FRACTURADA DE AMÉRICA

FELIPE OLIVER

los cortes intrapalabras remiten a las incisiones que experimenta el cuerpo al momento de ser maltratado $(2007, \mathrm{I} 48)$.

Siguiendo con esta línea analítica, o sea la constante fragmentación del verso, el fenómeno puede leerse también a partir de la desintegración de la realidad del yo lírico en una serie de experiencias confusas y delirantes. Ahora, para armar esta lectura es necesario primero resumir las características esenciales del poemario: Zonas de peligro espacialmente enfrenta al lector a la ciudad de Concepción. De igual modo, y tomando todas las reservas, es posible afirmar que el yo lírico "narra” el tránsito por las calles de la ciudad sureña, por el barrio de la prostitución de Orompello, y deteniéndose un momento en el Yugo Bar para instalarse en la parte final en el Hotel King con una compañera sexual. Durante este recorrido el yo lírico constantemente establece un paralelo entre el peligroso transitar por las calles del sur y el cuerpo humano. Las zonas de peligro responden tanto al espacio físico, esto es Concepción, como a la anatomía del otro, ese "tú" al que se interpela una y otra vez. Este desdoble constante del yo a "lo otro", (a veces un tú, a veces un nosotros y a veces un él o ello) deviene en una caótica acumulación de imágenes. Citando a Marcelo Garrido:

El sujeto amante, encalado en el texto, es un sujeto que, entre la muchedumbre incierta de cuerpos, sufre de delirios, alteraciones de la realidad textualizados bajo el código de la crónica. Por lo tanto es el relato crítico inserto en una suerte de clima pesadillesco el que va desmantelando el discurso erótico, desatando un contexto de imágenes inciertas del todo negativas $(2007,2)$. 
De acuerdo con la lectura de Garrido, el verso se fractura como resultado de la incoherente percepción y codificación de la realidad del yo lírico. Si previamente señalé que el recorrido del poeta es descriptible, en tanto que podemos establecer una cronología del desplazamiento, es necesario complementar la idea del recorrido añadiendo que éste está marcado "por toda clase de atisbos, entrevisiones, relámpagos de eso otro que está o que se presupone que está por debajo del nivel en el cual los relatos en sentido estricto resultan factibles" (Rojo, I996, I4). En otras palabras, el verso se fractura pues la realidad es en sí inaprensible y por lo tanto el poema si pretende ser mimético debe casi como obligación desmantelar cualquier discurso más o menos congruente.

Ahora, es interesante que Garrido utilice la palabra “crónica”. La descripción puede hacerse aun más nítida y afirmar que en Cipango hay una presencia muy marcada de un tipo específico de crónica: la crónica de Indias. Si bien es cierto que este motivo será ampliamente explotado en Diario de navegación, donde el yo lírico incluso reproduce el castellano colombino, ya en el multicitado poema "Zonas de peligro" encontramos los versos siguientes:

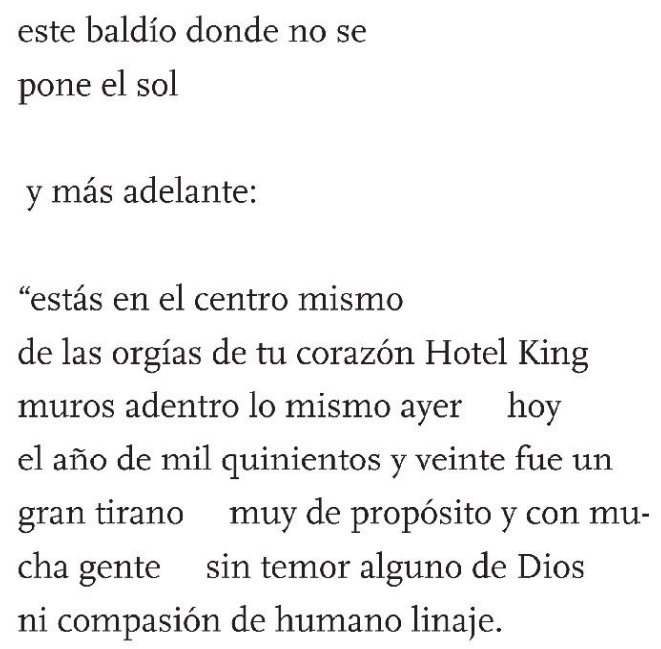


TOMÁS HARRIS Y LA MEMORIA FRACTURADA DE AMÉRICA

FELIPE OLIVER

El hipograma, para usar la terminología de Michael Riffaterre ${ }^{4}$, es la célebre sentencia de Carlos V sobre la bastedad de su imperio. Los versos este baldío donde no se/pone el sol, dicho sea de paso, se repiten una y otra vez a lo largo del poemario, por lo que es imposible pensar el texto sin vincularlo culturalmente con el discurso sobre el descubrimiento y la conquista de las Indias. Idea que se refuerza, ya ha sido mencionado, por la construcción de formas anacrónicas del lenguaje que recuerdan el castellano colonial: muy de propósito y con mu-/cha gente/ sin temor alguno de Dios/ ni compasión de humano linaje. De igual modo, en el poema se verifica una metáfora en tanto que el yo lírico se identifica con el monarca europeo pues ambos ocupan la misma posición espacial. Es decir, el yo lírico, que ahora se habla así mismo en segunda persona, ocupa "la angosta y delgada faja de muerte" tal como otrora la ocupó Carlos V sin temor alguno de Dios. La voz narrativa y el Rey son ya la misma persona, se ha producido una sustitución.

Todavía quedan aún varias cuestiones por resolver. La primera de ellas responde a la angosta y delgada faja de muerte a la que sea alude una y otra vez en el poemario. Transcribamos un poema como ejemplo:

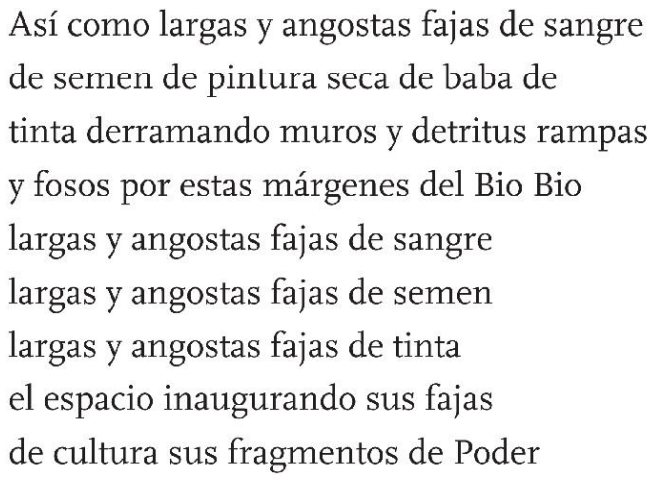

4 De acuerdo con Riffaterre, el hipograma se define como un resto, una huella de frases pre-existentes en textos anteriores. Véase el texto citado en la bibliografía. 


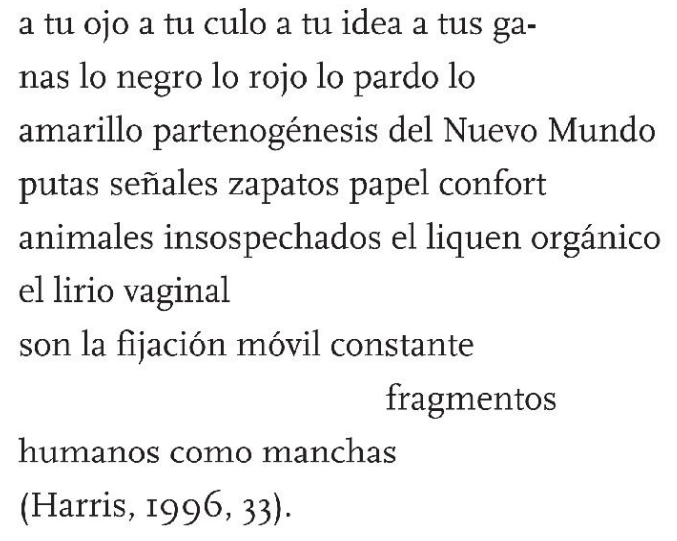

En una primera lectura desconcierta en la línea novena el sustantivo Poder, con mayúscula, y los versos a tu ojo a tu culo a tu idea a tus ga-
nas lo negro lo rojo lo pardo lo...

El poema parece dar vueltas alrededor de la violación, que implica siempre un acto de poder antes que un trance sexual, sin mencionarla explícitamente. Ahora, si buscamos en el interior del poema una metonimia la hipótesis se confirma. A partir del quinto verso hay una reiteración del sonido "fa", (contenido en la palabra "fajas"), mientras que en el verso undécimo se repite el sonido "lo". El resultado final es "falo", por lo que se produce un desplazamiento semántico entre la descripción de la geografía del Bío-Bío en particular y de Chile en general (largas y angostas fajas) y el órgano reproductor masculino, signo de dominación y poder utilizado en la conquista del Nuevo Mundo. Veamos otro ejemplo: 
TOMÁS HARRIS Y LA MEMORIA FRACTURADA DE AMÉRICA

FELIPE OLIVER

Hotel King I

(Genet)

Una última bombilla ilumina los cristales, esta

transparencia.

la muerte está atenta-me señalas:

vivo el ojo al charqui-y me sonríes.

Esta negra con un dedo en los labios incita al

silencio

y en los muros, en los vértices resplandecen

nuestros deseos.

Estamos en el Hotel King

en el centro mismo de las orgías de tu corazón.

Y ella es un solo ojo al fondo de una pieza larga.

El agua, afuera, está inmóvil en las charcas.

Nuestros cuerpos se menean, pero apenas se nota

para no

espantarla.

Ahora ella entra en escena.

Sus muslos son tibios y aguijan mis ijares.

Hago un esfuerzo para no dar coces y relinchar.

(Harris, I996, 43)

Este poema propone un desdoble constante del espacio exterior (el agua, afuera, está inmóvil en las charcas, al espacio interior (estamos en el Hotel King). $\mathrm{Y}$ como un eco de este movimiento se produce también un cambio en el registro lingüístico, pues el yo lírico rápidamente pasa de la tercera persona al tú, la muerte está atenta—me señalas, y de ahí a la primera persona del plural, nuestros deseos.../ nuestros cuerpos se menean. El poema termina con la muerte, ese "ella" que estaba solo como un testigo, ascendiendo entre la anatomía de los amantes, uniéndose así a la copula. El acto erótico deviene en la "totalidad de un solo cuerpo colectivo carente de amor" (Garrido, 2007, 3). El último 
verso nos enfrenta a la “animalización” de la voz narrativa que, insistimos, debe leerse como un yo colectivo. Ahora, la metáfora es crucial pues se trata específicamente de un caballo. Es decir, el yo lírico se identifica no con Genet, o al menos no de manera completa a pesar de estar nombrado en el título, sino con la figura de un rey, pues los monarcas por convención se asocian con los equinos. Para apoyar la metáfora basta con traducir al castellano el nombre del hotel. Y por si lo anterior no fuera suficiente, en los últimos versos se produce una metonimia a partir de la reiteración del fonema "p": Nuestros cuerpos se menean/ pero apenas se nota/ para no/ espantarla. En el contexto inmediato, es tentador pensar en la sombra de Pinochet (sobre todo al relacionar este poema con "Zonas de peligro", en donde se alude a Carlos V bajo el calificativo de "gran tirano"). Ampliando la mirada, el verso parece ofrecer una alusión al padre, cuya similitud con el rey es innegable en tanto figura el poder, orden, disciplina o castigo. Y una vez que hemos llegado a este punto, sólo queda recordar que la institución política y económica por excelencia durante la colonia fue la encomienda, título que otorgaba el Rey en favor de un súbdito español con el objeto de que éste percibiera los tributos o los trabajos que los súbditos indígenas debían pagar a la monarquía. A cambio, el encomendero debía cuidar del bienestar de los indígenas en lo espiritual y en lo terrenal, asegurando su mantenimiento y su protección, así como su adoctrinamiento cristiano. Por lo tanto, de encomendado a encomendero, y de este al Rey, el monarca ejercía su paternidad sobre todo el imperio.

La violcncia que cruza y marca "Zonas de Pcligro" ha salido del Chilc dictatorial para ingresar a una esfera más amplia: la Historia, con mayúsculas, de nuestro continente. Lo poetizado es la conquista. La fractura constante del verso puede leerse a partir del hecho mismo de que el discurso sobre la historia de las Indias se construyó desde la visión exclusiva de los vencedores. La cópula 
TOMÁS HARRIS Y LA MEMORIA FRACTURADA DE AMÉRICA

FELIPE OLIVER

en el Hotel King incluye a la muerte, lo que no debe olvidarse pues así como nace ese sujeto colectivo, o precisamente por eso, como contraparte muere también la individualidad del yo lírico. Por añadidura, la voz narrativa tan marcada de los primeros poemas forma ya parte del pasado del poemario, tal como se perdió un pasado de nuestra historia con la violación de las Indias (y aquí el doble sentido es deliberado). Salvo algunos textos rescatados y editados por León Portilla, el discurso de la conquista se escribió "oficialmente" desde las cartas, diarios, crónicas, etcétera, de los militares, frailes y autoridades civiles europeos. La otra cara de la moneda, el discurso de los indígenas fue, como los versos de Cipango, abruptamente silenciado, lo que equivale a decir que nuestra historia es el producto de un discurso fracturado.

Una vez que ha sido señalada la emergencia del discurso de la crónica de Indias en la poesía harriana, el análisis puede y debe abrirse a lo que en términos de Bajtin denominaríamos como polifonía. Es decir, al nutrido diálogo entre discursos que caracteriza la poesía de Harris: la historia, el cine, el discurso erótico, el género detectivesco (en tanto que el yo lírico recorre las calles de la ciudad descubriendo un crimen o la violencia a cada paso). Citando a Juan Herrera,

Cipango genéricamente se perfila como parodia de una multiplicidad de discursos, especialmente de los textos coloniales americanos, con el objeto de establecer un paralelo entre la relación de poder que la escritura del script revelaba bajo las condiciones de la ciudad letrada y las nuevas relaciones que el escritor y su escritura minoritaria revelan en un espacio degradados $(2005, \mathrm{I} 2)$.

Estas palabras ofrecen bastante materia para comentar. Sobre la importancia de los textos americanos es poco lo que podemos añadir, son el Contra-relato con mayúscula del poemario; son el recurso que permite al poemario salir de 
su contexto inmediato, esto es la dictadura militar chilena a la que se alude a través de la tortura, los campos de exterminio, la mención explícita al año de I973, para ingresar en una esfera más amplia. Más aún, los intertextos coloniales construyen una visión desencantada de la historia en donde la violencia de la conquista encuentra su prolongación natural varios siglos después en el gobierno militar a través de dispositivos disciplinarios y de dominación de extrema violencia como la tortura y la violación. Sin embargo, aun no he dicho nada sobre los diferentes poetas con los que el yo lírico explícitamente se identifica a lo largo del poemario, siempre en clave paródica: Allen Ginsberg, Genet y, en primerísimo lugar, Baudelaire. Aun cuando este último no es nombrado, es indudable que en el motivo del recorrido por las calles y el subsiguiente horror/fascinación por la muchedumbre, la irrupción del mass-media en la geografía urbana, y los neones iluminando la atmósfera de una vulgar artificialidad, el yo lírico de Harris no hace sino reproducir "los patrones del flânéur baudelairiano" (Rojo, I996, I3).

Por otra parte, Tomás Harris se identifica con los poeta malditos en general y con el autor de Las flores del mal en particular por diversas razones: Baudelaire, no hay que olvidarlo, luchó por conquistar la autonomía poética en un campo literario dominado por “el matrimonio" del político con el poeta de salón. Harris traslada el ejemplo al cronotopo e historia americana reconociendo, ya desde el discurso de la conquista, una relación estrecha entre el intelectual y el poder estatal. Matrimonio que encuentra un paralelo varios años después con la dictadura y los intclectualcs del rćgimen. De cstc modo, Harris rescata la figura del poeta como el crítico maldito de su tiempo y se reserva y, al mismo tiempo, asume la misión de incorporar al patrimonio cultural un repertorio propio del material poético. Así, combinados la crónica de indias con el género 
TOMÁS HARRIS Y LA MEMORIA FRACTURADA DE AMÉRICA

FELIPE OLIVER

detectivesco, los grabados de Goya con el cine de James Bond, etcétera, Tomás

Harris cuestiona desde el Sur al campo metropolitano

\section{REFERENCIAS BIBLIOGRÁFICAS}

Adorno, Theodor. "Discurso sobre lírica y sociedad”. Notas de literatura. Barcelona: Akal, I962.

Cohen, Jean. “La versificación”. Estructura del lenguaje poético. Madrid: Gredos, I977, 5I-I03.

Garrido, Marcelo. “Cuerpo y Baldío en la poesía de Tomás Harris”. Universidad de Concepción. 2007. www2.udec.cl/ docliter/docs/artilinea/harris.pdf.

Harris, Tomás. Cipango. Santiago de Chile: Fondo de la Cultura Económica, 1996.

Herrera M, Juan. “Hacia una estética de la desaparición en la poética de Tomás Harris". In: Acta Literaria, n. 30, 2005, 9-18.

Lacan, Jacques. "Metáfora y metonimia (I)". La Psicosis. Barcelona: Paidós, I984.

Riffatere, Michael. Semiotics of poetry. Bloomington: Indiana University Press, I984.

Rojo, Grínor. "Tomás Harris o de la fiebre del oro en Orompello". In: Harris, Tomás. Cipango. Santiago: Fondo de la Cultura Económica, I996.

Sepúlveda Eriz, Magdalena."Luces en la ciudad. Dictadura y simulacro en 'Tomás Harris”. In: Atenea, n. 496, II Sem. 2007, I45-I58. 


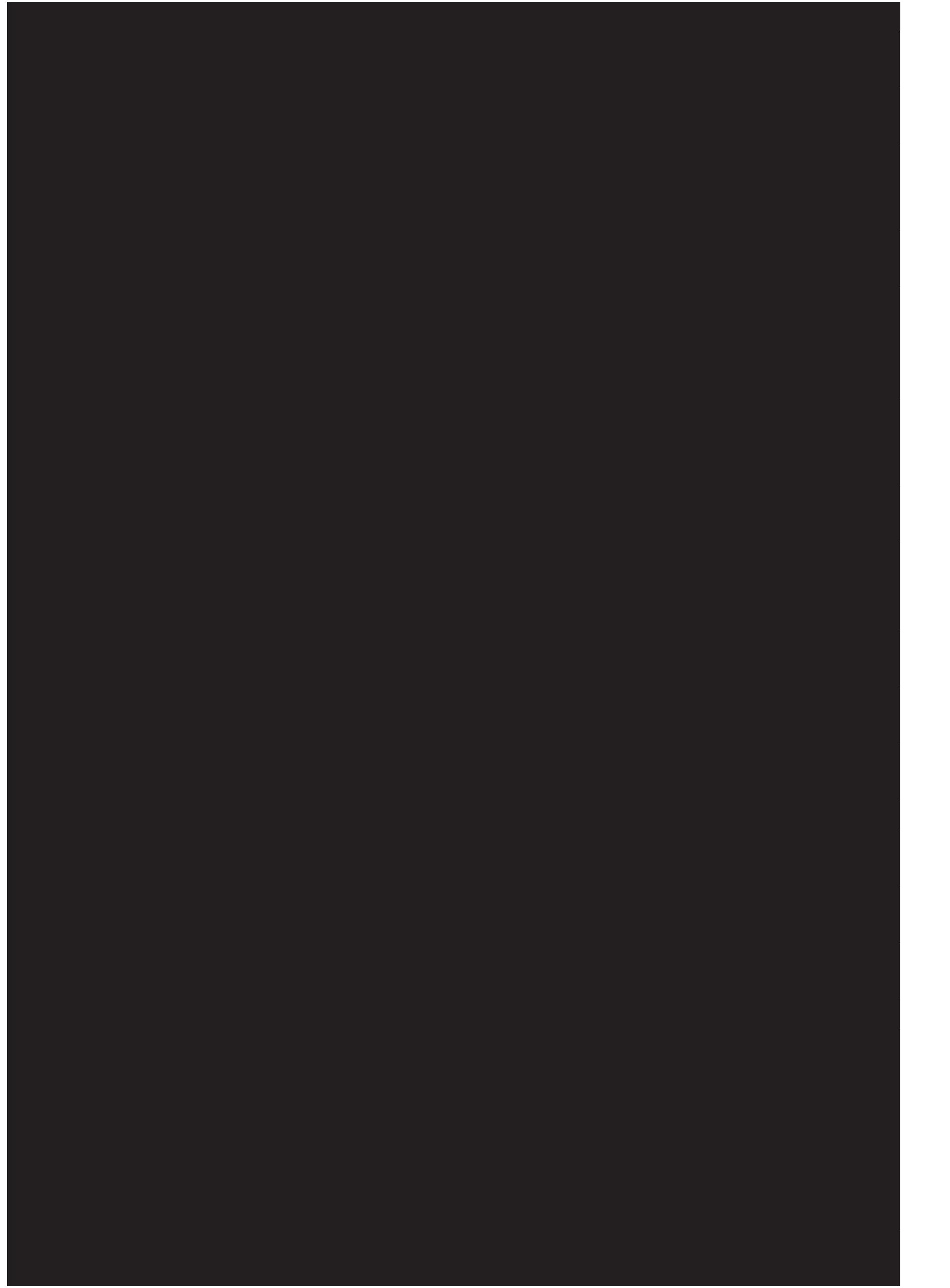




\section{Los bordes del canon}

y la centralidad del

mal: La literatura

nazi en América de

Roberto Bolaño

\section{Walfrido Dorta Sánchez}

Walfrido Dorta realiza su doctorado en el programa Hispanic and LusoBrazilian Literatures and Languages del Graduate Center (CUNY).

Investiga actualmente la obra de los escritores cubanos del grupo Diáspora(s). Ha publicado diversos ensayos sobre literatura cubana y latinoamericana, y el libro El testigo y su lámpara: para un relato de la poesía como conocimiento en Gastón Baquero (Eds. Unión, La Habana). 
CARACOL 5 / VÁRIA

PALABRAS CLAVE:

Roberto Bolaño; nazi;

mal; canon; literatura

latinoamericana.

KEYWORDS

Roberto Bolaño; Nazi; evil; canon; Latin American literature.
RESUMEN

El ensayo aborda La literatura nazi en América de Roberto Bolaño a partir de sus conexiones con La vida de los hombres infames y Los anormales de Michel Foucault, y con algunas conceptualizaciones de Rüdiger Safranski en torno a la ideología nazi en El Mal o El drama de la libertad, y de Roberto Esposito en torno al mal en Confines de lo político. Me interesa pensar las distintas inscripciones de lo nazi en el libro de Bolaño. Propongo que La literatura nazi... se articula alrededor de dos dinámicas: por un lado, la relación conflictiva entre normalización y la fuga/lo monstruoso; y por otro lado, los vínculos entre la centralidad del mal y el trazado de los bordes del canon de la literatura latinoamericana que el diccionario realiza, no tanto colocado en el afuera de este canon, sino en sus límites. 
LOS BORDES DEL CANON Y LA CENTRALIDAD DEL MAL: LA LITERATURA NAZI EN AMÉRICA DE ROBERTO BOLAÑO WALFRIDO DORTA

\begin{abstract}
This essay focuses on Roberto Bolaño's La literatura nazi en América and its links with Michel Foucault's La vida de los hombres infames and Los anormales. It also analyzes the relationships between Bolaño's book and some conceptualizations of Rüdiger Safranski's El Mal o El drama de la libertad on Nazi ideology and of Roberto Esposito's Confines de lo político on evil. The essay aims at explaining the inscriptions of the Nazi in Bolaño's book. It claims that La literatura nazi... revolves around two dynamics: on the one hand, the complex relationship between normalization and the escape/ the monstrous; on the other hand, the links between the centrality of evil and the tracing of the edges of the canon of Latin American literature that is done by the dictionary, which is not placed outside of this canon, but in inside boundaries.
\end{abstract}


La literatura nazi en América [LLN] de Roberto Bolaño guarda con el resto de su producción literaria más de un punto de contacto. Pienso que la obra del autor chileno podría entenderse a partir de una distinción fundamental: es una máquina que hace proliferar incesantemente historias; un mecanismo aparentemente incontrolado provoca la multiplicación de narrativas interconectadas, obligando al lector a un verdadero ejercicio de destreza hermenéutica. LLN participa de esta organización expansiva, sólo que otros imperativos constriñen tal expansión. El diccionario como dispositivo obliga a cierta contención, lo cual no impide que $L L N$ pueda ser visto como un universo en el que nos es presentada, mejor, revelada, una comunidad de infames, unidos por cierto aire de familia, en virtud de las diferentes adscripciones de sus vidas y sus obras a una idea o a una ideología de lo nazi. Quisiera explorar las dinámicas a partir de las cuales se articula este universo de conexiones, e indagar en los diálogos que pueden establecerse entre el libro de Bolaño y algunos discursos filosóficos.

Es posible establecer varias conexiones entre La literatura nazi en América $[L L N]$ y el proyecto de libro que Foucault no concluyó, tal como éste queda expuesto en “La vida de los hombres infames”. El libro de Bolaño es, como el del francés, una "antología de vidas" (Foucault, I996a, I2I). LLN no se ciñe sólo al recuento de los avatares de los autores que recoge. Incluye como parte esencial las citas de algunos discursos que dicen las infamias de estos personajes: los fragmentos de sus libros, poemas, textos en general, pero sobre todo las críticas a éstos; las opiniones de sus contemporáneos. De manera que el discurso descriptivo, fijador, del diccionario, sc desdobla cn otras cnunciacioncs quc completan las caracterizaciones de los autores, desperdigadas a lo largo de todo el libro. Como en la ficha de Andrés Cepeda Cepeda, a quien sus críticos califican de "paleonazi, tarado, abanderado de la burguesía, títere del capitalismo, agente de la CIA, poetastro de intenciones cretinizantes... esbirro de las cloacas, 
LOS BORDES DEL CANON Y LA CENTRALIDAD DEL MAL: LA LITERATURA NAZI EN AMÉRICA DE ROBERTO BOLAÑO WALFRIDO DORTA

profeta de baratillo, violador de la lengua española, versificador de intenciones satánicas, producto de la educación de provincia, rastacuero, cholo alucinado" (Bolaño, 2005, 79-80). Tales son los equivalentes de los discursos judiciales, punitivos, admonitorios, que Foucault se proponía recoger en su recopilación. A través de ellos, y sobre todo de la reconstrucción que constituye el dispositivo del diccionario, nos llegan las acciones y palabras que no deberían-según un imperativo canónico de representación y de proliferación de los discursos-haber circulado, o haberse inscrito siquiera en la trama de lo histórico y lo factual: “lo 'ínfimo', lo que no se dice, lo que no merece ninguna gloria, y por lo tanto "infame”" (Foucault, I996a, I36). Las existencias y las obras de cualquiera de estos autores vienen a ser "rescatadas" por el diccionario, y alejadas de su destino de borradura, de no dejar rastro, en virtud de sus presumibles valencias oscuras, su falta de gloria.

El diccionario otorga distinción a seres y discursos abocados a engrosar los flujos del anonimato, y los coloca en el plano de la leyenda, así como los relatos ante los cuales se maravilló Foucault hacían con otros hombres infames: ese plano en el que lo ficticio y lo real se confunden, y en el que los sujetos se recubren "con tantos prodigios... tantos atributos imposibles que es, o casi es, como si no hubiese[n] vivido". Esos "relatos insistentes" que se transmiten hacen que adquieran "el espesor histórico propio de alguien que hubiese existido" (Foucault, I996a, I26). El texto de Bolaño va a aprovechar al máximo justamente esta pendularidad entre el prodigio y el espesor histórico, convocando implícitamentc al lector a descifrar posibles correspondencias cntrc los retratos de los infames y las imágenes públicas de algunos escritores canónicos de la literatura latinoamericana, por ejemplo.

Los personajes no dotados "de ninguna de [las] grandezas instituidas y valoradas"; las vidas "animadas por la violencia, la energía y el exceso en la maldad, 
la villanía, la bajeza, la obstinación y la desventura" (Foucault, I996a, I24), son la trama de $L L N$. Este diccionario se articula alrededor de una dinámica tensa entre normalización y fuga; entre la regularización y lo indecidible de los sujetos que quiere someter a esta regularización. Es un proyecto que persigue esclarecer la "leyenda negra" de estos autores filonazis (se citan sus años de vida, sus libros, las editoriales que los publicaron: se construye un universo referencial estable), en contraposición a la "leyenda dorada” que alimenta el canon, la literatura establecida, reconocida en los circuitos de producción discursiva. El diccionario, que responde a unos protocolos según los cuales debe ser un dispositivo normalizador, organizador, lucha todo el tiempo con las zonas de incertidumbre, las brumas que rodean y que son constitutivas de ciertos eventos, datos, filiaciones, relacionados con los autores que aspira a fijar, y al mismo tiempo produce inevitablemente esas zonas, puesto que las realizaciones de esa "leyenda negra” (“sin tradición”) no pueden visibilizarse sino a través de un proceso discontinuo, "a través de rupturas, borrones, olvidos, entrecruzamientos, reapariciones" (Foucault, I996a, 126).

El filósofo francés propone en “La vida..." que desde el siglo XVII emerge en Occidente un arte del lenguaje cuya tarea será “hacer aflorar lo que permanecía oculto, lo que no podía o no debía salir a la luz ... los grados más bajos y más persistentes de lo real”; con lo que se crea un nuevo imperativo "que va a constituir ... la ética inmanente del discurso literario de Occidente": "obligar a decir lo 'ínfimo', lo que no se dice, lo que no merece ninguna gloria ... lo 'infame”; buscar "lo más prohibido y lo más cscandaloso" (1996a, 136, 137).

Las narrativas proféticas, mesiánicas, regeneracionistas, producidas por los autores de $L L N$; las blasfemias, imprecaciones, maldiciones que en ellas proliferan; las distopías, los contra-relatos o imaginarios contra factuales; las tramas terroristas; las rupturas de las lógicas de representación narrativa; las 
LOS BORDES DEL CANON Y LA CENTRALIDAD DEL MAL: LA LITERATURA NAZI EN AMÉRICA DE ROBERTO BOLAÑO WALFRIDO DORTA

narrativas imposibles, excesivas..., podrían verse a la luz de esta intensificación de lo literario tal como lo expone Foucault. Ellas mismas son una reduplicación de ese imperativo de representación que impulsa a "decir los más comunes secretos... lo más indecible, lo peor, lo más secreto, lo más intolerable, lo desvergonzado" (Foucault, I996a, 137).

En muchas ocasiones los autores del diccionario se ven a sí mismos a través de este más, de este exceso de verdad que sus discursos portarían. Así Amado Couto, por ejemplo, cuyas palabras apuntan a la lógica estoica y sacrificial que lleva a cumplir inflexiblemente ese imperativo de representación. Justamente en virtud de realizar tal imperativo, es que algunos autores se asumen, como en el caso de Couto, con valores más auténticos que los autores "reales", con lo que se construye una axiología inversa que busca la suplantación, la ocupación de un lugar usurpado por los autores canónicos. En esta lógica, Rubem Fonseca sería para Couto alguien que "vive en una pecera de tiburones metafísicos", mientras el renegado, el denegado que es Couto, se ve a sí mismo como el que vive "entre pirañas" (Bolaño, 2005, I28).

Por otro lado, creo que los infames de $L L N$ pueden entenderse además a través de la figura del anormal, tratada también por Foucault; específicamente, a partir de la figura del monstruo humano, en tanto muchos de los autores del diccionario emergen como sujetos que reúnen en sí tal variedad de rasgos de naturaleza contradictoria y excluyente, que se convierten en rarezas, fugas, desviaciones, 'objetos de culto'. El diccionario sería así una galería de monstruos, a la mancra de csos cspectáculos de fcria dcl XIX, los Freak Shows, o los Congress of Human Oddities.

En esa pendularidad entre el prodigio y el espesor histórico, a la que aludía más arriba, se trazan los perfiles de estos autores. El monstruo (monstrum) denota etimológicamente lo prodigioso, el suceso sobrenatural. Sobre el étimo 
del verbo monere ('avisar', 'advertir') se forma la palabra, y de ella se derivan verbos como monstrare o demonstrare. No hay que olvidar entonces la fuerza deíctica de lo monstruoso. El monstruo se exhibe, se muestra, se exotiza en su exposición monstruosa, pero al mismo tiempo señala admonitoriamente que él constituye una violación excesiva de la norma, del canon. La mostración del monstruo humano no se agota en sí misma como espectáculo, sino que implica una relación conflictuada con la norma.

Así, no sólo deberíamos leer $L L N$ colocados en nuestra función voyeur (ciertamente, el lector podría dejarse ganar por una fruición voyeurística, esperando encontrar el siguiente anormal; los siguientes excesos, desvíos, desproporciones, cuál de ellos más grandes que los anteriores), sino proyectando el diccionario contra el fondo poderoso del canon, de la norma que dictaría la borradura de estos discursos y sujetos, su desaparición. Esta función norma o canon puede ser asumida por los constructos 'literatura del Boom', 'Literatura Latinoamericana', 'Literatura Caribeña'..., o incluso, 'Historia de América Latina'.

Esta norma se concreta en las "instituciones de control, con toda una serie de mecanismos de vigilancia y de distribución del orden" (Foucault, I996b, 6I): Academias, premios literarios, crítica especializada, diccionarios autorizados; todas las instancias de las cuales se fugan (no caben en ellas) los autores de $L L N$, el cual deviene un dispositivo que adopta miméticamente la forma autorizada del diccionario para descentrar algunas de sus proyecciones legitimadas.

En tal sentido es que creo que $L L N$ no se coloca tanto fuera del canon que suponen cualquicra de csos constructos cnumcrados más arriba, como delinca los contornos de ese canon, sus límites discursivos e ideológicos. A fin de cuentas, los ideologemas que estructuran las narrativas nazis de los autores del diccionario articulan también las narrativas que forman parte del repertorio legitimado. Sólo que las primeras son las realizaciones desquiciadas, incontroladas, 
LOS BORDES DEL CANON Y LA CENTRALIDAD DEL MAL: LA LITERATURA NAZI EN AMÉRICA DE ROBERTO BOLAÑO WALFRIDO DORTA

inadmisibles, de unas narrativas canónicas que proponen también la búsqueda y la realización de construcciones totalizadoras y excluyentes (lo 'esencial latinoamericano' o 'americano', etc.), y que giran alrededor de los significantes identidad, nación, particular, diferencia, regeneración, comunidad. Las primeras son las máquinas 'enloquecidas', confrontadas a una producción discursiva similar de indagación identitaria; y como tal son máquinas peligrosamente desinhibidas - en el sentido al que alude Safranski con respecto a Hitler, como "la última desinhibición de la modernidad" $(2006,246)$.

De manera que conviene recordar, como advierte Foucault, que "[l]o que constituye a un monstruo humano en un monstruo no es simplemente la excepción en relación con la forma de la especie, es la conmoción que provoca en las regularidades jurídicas ... El monstruo humano combina a la vez lo imposible y lo prohibido" (1996b, 6r).

Justo en ese cruce entre lo imposible y lo prohibido se juega la inteligibilidad como autores y como literatura de los sujetos y los discursos que recoge $L L N$. En tanto éstos son el reverso pesadillesco de las líneas maestras de la modernidad literaria (latino)americana, o, en una visión más comprometedora, el centro oscuro, desencadenado (Safranski, 2006, 230), que esa misma modernidad alberga, corren el riesgo del olvido, de la invisibilidad, de la impertinencia. En varias ocasiones se apunta a esta condición especular negativa. Así, se dice que El Verdadero Hijo de Job, de Harry Sibelius, es el "espejo negro" de La Europa de Hitler de Arnold J. Toynbee (Bolaño, 2005, I31); o se alude a Ramírez Hoffman como "cl doblc ncgro dc Gary Snydcr" (Bolaño, 2005, 209).

En una dimensión más arriesgada, porque apunta a la definición misma de la literatura a través de una aporía, Jules Defoe (uno de los alias de Ramírez Hoffman) sostiene que la literatura debe ser escrita por gente ajena a ella, y que “[l]a revolución pendiente de la literatura... será de alguna manera su abolición. 
Cuando la Poesía la hagan los no-poetas y la lean los no-lectores" (Bolaño, 2005, 213): la indistinción de saberes y de prácticas, la fusión de campos y de experiencias, desiderátum vanguardista por excelencia, aparece aquí signada por el aura negacionista de los escritores infames del diccionario.

En un momento del capítulo dedicado a Carlos Ramírez Hoffman creo que quedan condensadas algunas de las claves esenciales para leer $L L N$. Esa voz del futuro que atraviesa y sostiene todo el diccionario, 'originada' al menos después de 202I (fecha de la muerte de Zach Sodenstern, uno de los autores), nos dice con respecto a Ramírez I Ioffman que “[s]u paso por la literatura deja un reguero de sangre y varias preguntas realizadas por un mudo. También deja una o dos respuestas silenciosas" (Bolaño, 2005, 209). Reaparece así el trazo aporético, inasimilable a una lógica reconciliatoria. Tal trazo remite a la topología aludida en otro momento de mi ensayo, ese borde del canon delineado por los autores del diccionario; el límite constitutivo de este canon, no su exterioridad. De manera que lo que se disputa es la inscripción en el campo literario, o en otras palabras, el reconocimiento de una capacidad de enunciación.

Las narrativas de los autores filonazis son el ruido salvaje que una comunidad literaria legitimada se niega a reconocer, pero que persiste en sus derivas más incontrolables y perturbadoras, conformando el repertorio de inscripciones de lo nazi en el diccionario ideado por Bolaño. Hablo del racismo; lo abyecto; el castigo de los cuerpos; la eugenesia; las lógicas implacables construidas sobre premisas delirantes; las fobias de la modernización; el imperativo tanapolítico de la biopolítica y cl paroxismo del paradigma inmunitario de la modernidad (Esposito, 2006, I9, 20); el deseo confesado o metaforizado de transformar la fuerza en barbarie (Safranski, 2006, 23I); la apelación reiterada a lo sagrado y a una "supermoral" (Safranski, 2006, 232) que legitimaría los imaginarios de aniquilación en esas narrativas, y sobre todo, la proliferación 
LOS BORDES DEL CANON Y LA CENTRALIDAD DEL MAL: LA LITERATURA NAZI EN AMÉRICA DE ROBERTO BOLAÑO WALFRIDO DORTA

de formas discursivas totalitarias que se pueden rastrear a lo largo del diccionario, y que constituyen los lugares de producción del mal radical, tal como se manifiestan las figuras de esas formas, según Esposito. En primer lugar, el Enemigo interno, que crea "la verdadera compacidad totalitaria" y que posibilita "la ‘maldición' del otro... por la autoproclamación de sí mismo como bien” (I996, I56, I57): judíos, indios, comunistas, homosexuales, encarnaciones de lo otro aparecidas en los discursos de los autores de LLN. En segundo lugar, el Supersentido ideológico: la insensatez como "supersentido terriblemente funcional en su pretensión de validez absoluta" (I996, I58), incrustada en el centro de narraciones como las de Harry Sibelius (Bolaño, 2005, I3I-I34) o las de Argentino Schiaffino (Bolaño, 2005, I74, I75). Y en tercer lugar, la Mímesis de lo Absoluto, en tanto el "mal es radical... en la medida que se presenta como actuación de una 'norma' y norma absoluta él mismo" (Esposito, I996, I59).

Por otro lado, la empresa de reconstrucción mimética según una lógica implacable que lleva a cabo Edelmira Thompson de Mendiluce (Bolaño, 2005, I822), y que da lugar a la construcción de un espacio amueblado en su finca y a su libro La Habitación de Poe (justamente en este orden causal), podría asimilarse no sólo a una "parodia de la reescritura como estética", tal como argumenta Manzoni $(2006,23)$ de manera creo reducida, sino también a la lógica nazi según la cual, como dice Safranski, hay un imperativo de configuración de la realidad según una imagen de esa misma realidad; un imperativo de "hacer verdadero un delirio realizándolo" $(2006,240)$. Asimismo, creo que en esta lógica pucdc cnmarcarsc cl proyccto de Willy Schürholz (Bolaño, 2005, ı04-Іо7), regido por una progresión moldeadora de lo real, según la cual los primeros poemas que publica (frases sueltas y planos topográficos), los segundos (planos enormes con versos), y los siguientes libros (planos de campos de concentración y frases más articuladas), son la antesala de la roturación “sobre el desierto 
de Atacama" del plano "del campo de concentración ideal" y de "cinco vocales" grabadas en la tierra "y esparcidas arbitrariamente sobre la costrosa superficie del terreno". Emerge perversamente aquí el ideal fusional vanguardista y su deseo de indistinción entre lo real y lo artístico.

La literatura nazi en América es el gesto de Bolaño de hacer inteligibles los sonidos de una posible comunidad de renegados, en virtud de la centralidad de lo nazi (en sus diferentes modulaciones ideológicas y estéticas) en sus obras y en sus vidas. Se construye $L L N$ a partir de la tensión entre una voluntad estabilizadora, lapidaria (en el sentido de vida cerrada y definitiva que se relata), como la del diccionario, y una fuga recurrente de lo normalizado en virtud de la calidad monstruosa e infame de los autores incluidos. Lo hace también desde la incontestable dependencia que se establece entre la negativa del canon a escuchar unos discursos (ruidos que amenazan una configuración estable y permisible) y la persistencia fantasmagórica, acechante, de esos mismos discursos desinhibidos, que diseñan desde un borde-límite la cara negada de la modernidad y del canon de la literatura (latino)americana.

\section{REFERENCIAS BIBLIOGRÁFICAS}

Bolaño, Roberto. La literatura nazi en América. Barcelona: Seix Barral, 2005. Esposito, Roberto. Bíos. Biopolítica y filosofía. Buenos Aires: Amorrortu, 2006. Confines de lo político. Nueve pensamientos sobre política. Madrid: Trotta, 1996.

Foucault, Michel. "La vida de los hombres infames". En: La vida de los hombres infames. La Plata: Editorial Altamira, I996, I2I-I38. 
LOS BORDES DEL CANON Y LA CENTRALIDAD DEL MAL: LA LITERATURA NAZI EN AMÉRICA DE ROBERTO BOLAÑO WALFRIDO DORTA

"Los anormales". In: La vida de los hombres infames. La Plata: Editorial Altamira, I996, 6I-66.

Manzoni, Cecilia. "Biografías mínimas/ínfimas y el equívoco del mal”. In: Manzoni, Cecilia (ed.). Roberto Bolaño: la escritura como tauromaquia. Buenos Aires: Corregidor, 2006, I7-32.

Safranski, Rüdiger. El Mal o El drama de la libertad. Barcelona: Tusquets Editores, 2000. 


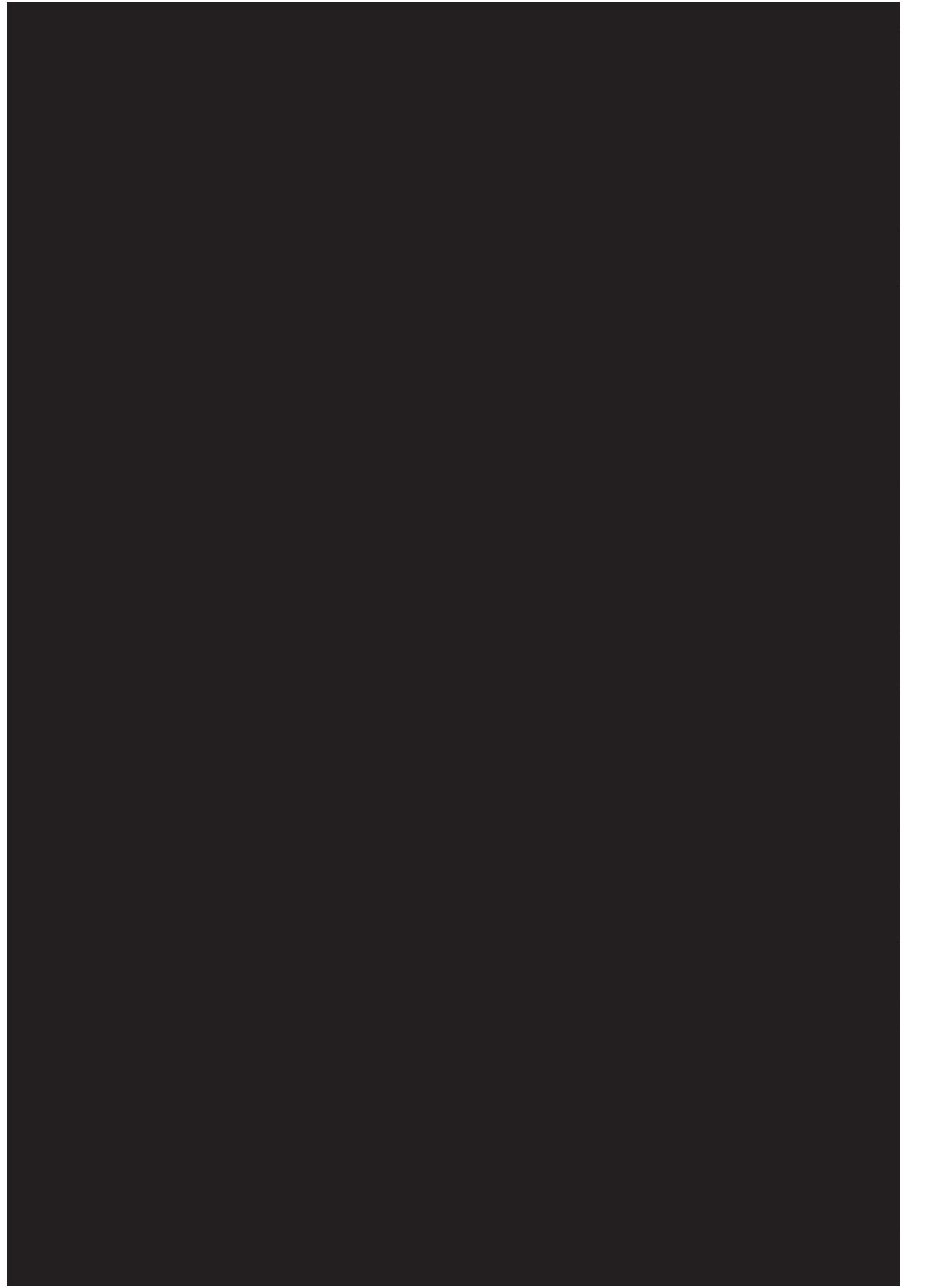

